\title{
Investigation of Lithium Transference Number in PMMA Composite Polymer Electrolytes Using Monte Carlo (MC) Simulation and Recurrence Relation
}

\author{
Renwei Eric Koh*, Cha Chee Sun, Yee Ling Yap, Pei Ling Cheang, and Ah Heng You \\ Faculty of Engineering and Technology, Multimedia University, 75450 Melaka, Malaysia
}

\begin{abstract}
In this study, Monte Carlo (MC) simulation is conducted with recurrence relation to study the effect of $\mathrm{SiO}_{2}$ with different particle size and their roles in enhancing the ionic conductivity and lithium transference number of PMMA composite polymer electrolytes (CPEs). The MC simulated ionic conductivity is verified with the measurements from Electrochemical Impedance Spectroscopy (EIS). Then, the lithium transference number of CPEs is calculated using recurrence relation with the $\mathrm{MC}$ simulated current density and the reference transference number obtained. Incorporation of micron-size $\mathrm{SiO}_{2}$ $(\leq 10 \mu \mathrm{m})$ fillers into the mixture improves the ionic conductivity from $8.60 \times 10^{-5} \mathrm{~S} / \mathrm{cm}$ to $2.35 \times 10^{-4} \mathrm{~S} / \mathrm{cm}$. The improvement is also observed on the lithium transference number, where it increases from 0.088 to 0.3757 . Furthermore, the addition of nano-sized $\mathrm{SiO}_{2}(\leq 12 \mathrm{~nm})$ fillers further increases the ionic conductivity up towards $3.79 \times 10^{4} \mathrm{~S} / \mathrm{cm}$ and lithium transference number of 0.4105 . The large effective surface area of $\mathrm{SiO}_{2}$ fillers is responsible for the improvement in ionic conductivity and the transference number in PMMA composite polymer electrolytes.
\end{abstract}

Keywords : Solid Polymer Electrolytes, Monte Carlo Simulation, Transference Number, Recurrence Relation, Ionic Conductivity

Received : 21 September 2020, Accepted : 3 November 2020

\section{Introduction}

Solid Polymer Electrolytes (SPE's) are electrolytes in solid form which consist of dissolved inorganic salts as charge carriers. SPEs eliminated the need for a separator. As a result, it is safer than traditional liquid and gel electrolytes. Besides, SPEs are extremely flexible and had better compatibility with most electrode materials. However, the application of SPEs on energy powered devices is hindered due to their high degree of crystallinity at room temperature. Due to the higher degree of crystallinity in traditional polymer electrolytes, i.e. PEO based polymer electrolytes, the motion on $\mathrm{Li}^{+}$ions among the polymer chain is stalled, and this causes the film to generate a significant amount of internal resistance that

*E-mail address: 1142701349@student.mmu.edu.my

DOI: https://doi.org/10.33961/jecst.2020.01459

This is an open-access article distributed under the terms of the Creative Commons Attribution Non-Commercial License (http://creativecommons.org/licenses/by-nc/4.0) which permits unrestricted non-commercial use, distribution, and reproduction in any medium, provided the original work is properly cited. results in low ionic conductivity and lithium transference number. Agrawal et al. [1] reported an ionic conductivity of $1 \times 10^{-7} \mathrm{~S} / \mathrm{cm}$ for $\mathrm{PEO}-\mathrm{LiClO}_{4}$ at room temperature in their study of solid polymer electrolytes system. Also, Pozyczka et al. [2] reported a lithium transference number of 0.054 to 0.059 for PEOLiTFSI SPEs with a molar ratio of $6: 1$ at $70^{\circ}$. Ionic conductivity and lithium transference number reported in the above studies for PEO SPEs are insufficient for practical application [3].

Moreover, ion transport in polymer electrolytes is a temperature-dependent process [4], ions received energy via thermal vibration to overcome the energy barrier so that they can have enough activation energy to hop to a nearby open vacant site. Thus, low activation energy and availability of open bond is essential for ionic transport in SPEs. Nevertheless, ionic conductivity and lithium transference numbers in SPEs can be boosted via the addition of ionic salts, plasticizers, and ceramic fillers [5-7].

Qian et al. [8] reported an improvement in ionic conductivity from $1.30 \times 10^{-7} \mathrm{~S} / \mathrm{cm}$ for $(\mathrm{PEO})_{16} \mathrm{LiClO}_{4}$ 
to $2.36 \times 10^{-4} \mathrm{~S} / \mathrm{cm}$ at room temperature when $50 \mathrm{wt} \%$ Ethylene Carbonate (EC) was incorporated into the mixture. The addition of plasticizers lowers the glass transition temperature, $T_{g}$ of the mixture, and this decreases the degree of crystallinity of polymer electrolytes at room temperature. As a result, the segmental motion of the polymer chain is enhanced, and the ionic conductivity increases. Xiao et al. [9] reported improvement in lithium transference numbers when $\mathrm{ZrO}_{2}$ particles were added into $\mathrm{P}(\mathrm{VDF}-\mathrm{HFP})-\mathrm{PMMA}$ matrix to create composite polymer electrolytes. They obtain lithium transference number of 0.28 to 0.41 for P(VDF-HFP)-PMMA- $\mathrm{ZrO}_{2}$ composite polymer electrolytes, an improvement from 0.16 without the addition of $\mathrm{ZrO}_{2}$ particles. The improvement in lithium transference number can be related to the large effective area of $\mathrm{ZrO}_{2}$ particles. The larger effective area provides $\mathrm{Li}^{+}$ions more conduction pathways in the polymer matrix, this improves the dynamic of the polymer chain, thus yielding higher lithium transference number.

Although improving the performance of SPEs is an area of intense interest of many researchers, but there is not much attention paid in understanding the ionic transport mechanism in SPEs using particle simulation. Furthermore, the random behaviour of ions in the free volume also makes studying the transportation characteristics and conduction phenomenon of ions in polymer electrolytes challenging. Dynamic Bond Percolation (DBP) is one of the earliest models that describe ions motion in a statistically disordered and dynamically rearranging medium [10]. Not until Wagner et al. [11] introduced Monte Carlo (MC) model, a three-dimensional model for thermally activated ion transportation in a multi-well energy structure.

In this work, a stochastic Monte Carlo method using random sampling technique is employed to develop a model capable of study SPEs with minimal needs of experiment. PMMA is used as the host polymer and $\mathrm{LiCF}_{3} \mathrm{SO}_{3}$ as the dopant salt. The advantages of using $\mathrm{LiCF}_{3} \mathrm{SO}_{3}$ as the dopant salt are because of its resistance to oxidation, lower activation energy and, non-toxicity [7]. Besides, larger anion radius of $\mathrm{LiCF}_{3} \mathrm{SO}_{3}$ ensure a higher degree of dissociation of salt in the polymer matrix, this ensures better segmental mobility and yielding higher ionic conductivity $[7,12]$. Furthermore, PMMA as a semi-crystalline polymer is selected as the polymer host because of its higher ionic conductivity and lithium transference number at room temperature compared to traditional PEO based system that are suffering from low ionic conductivity and transference number at room temperature due to their high degree of crystallinity $[13,14]$. Several studies also show that PMMA based polymer electrolytes have the potential to be fabricated into solid electrolytes used in solid-state batteries and solid-state supercapacitors [15-17].

$\mathrm{MC}$ simulations are used to study the effect of $\mathrm{SiO}_{2}$ fillers with different filler sizes on the ionic conductivity, and the transference number of PMMA- $\mathrm{LiCF}_{3}$ $\mathrm{SO}_{3}$ system is calculated using recurrence relation. The simulation results are then compared to the measurement data to ensure the validity of the model.

\section{Measurement and simulation of ionic conductivity and transference number}

\subsection{Sample preparation and characterization}

The samples were prepared using solution cast method [14,18]. Poly(methyl-methacrylate) (PMMA), Ethylene Carbonate (EC), Lithium Triflate $\left(\mathrm{LiCF}_{3}\right.$ $\left.\mathrm{SO}_{3}\right)$, and Silicon Dioxide $\left(\mathrm{SiO}_{2}\right)$ in the experiment are obtained from Sigma Aldrich. PMMA (Mw 996,000) were mixed the plasticizers, $\mathrm{LiCF}_{3} \mathrm{SO}_{3}$ and $\mathrm{SiO}_{2}$ inorganic fillers to yield a two-gram mixture. The mixture is first dissolved in Tetrahydrofuran (THF) solution and stirred using a magnetic stirrer until a homogenous solution is obtained. The homogenous solution was then poured into petri dishes and kept in a desiccator for drying until dry electrolyte films were obtained. Lastly, the films are cut into smaller samples, and the thickness of each sample was measured using micro-meter screw gauges and assembled into the battery cell for testing.

Gamry reference 600 series potentiostat was used for Electrochemical Impedance Spectroscopy (EIS) to characterize the polymer electrolytes samples. EIS is conducted in the frequency ranging from $0.1 \mathrm{~Hz}$ to $1 \mathrm{MHz}$ at room temperature with the sample sandwiched between two spring-loaded stainless-steel electrodes, and the ionic conductivity is calculated by using the following equation:

$$
\sigma=\frac{t}{R_{B} A}
$$

where $t(\mathrm{~cm})$ is the thickness of SPE film, $\mathrm{R}_{\mathrm{B}}$ is the bulk resistance of electrolyte obtained from the 
Nyquist plot, and $A\left(\mathrm{~cm}^{2}\right)$ is the contact area between the film and the electrode, which equates to $2.56 \mathrm{~cm}^{2}$ in this work.

DC polarization measurement was also performed using Gamry reference 600 series potentiostat using a polarization voltage of $20 \mathrm{mV}$ to obtain the initial current, $I_{o}$ and steady-state current, $I_{s}$. The transference number is calculated using Bruce-Vincent equation [19].

$$
t_{+}=\frac{I_{s}\left(\Delta V-I_{o} R_{o}\right)}{I_{o}\left(\Delta V-I_{s} R_{s}\right)}
$$

where $\Delta V$ is the polarization voltage, $R_{\mathrm{o}}$ and $R_{\mathrm{s}}$ are the resistance before and after polarization consisting of charge transfer resistance and passivating film resistance.

\subsection{Monte Carlo Simulation}

Interpreting the dynamics of ion in a dynamically disordered system like SPE is not an easy task as ions interact with each other in a polymer lattice, which is continually evolving with time. Nevertheless, by using MC simulation, it enables us to study the dynamic properties of ions by treating this complicated system as a grouping of many single ions. Hopping is the primary ion transport mechanism in a polymer. When an electric field was presence, $\mathrm{Li}^{+}$ ions start to drift; once the ions receive enough activation energy to overcome the energy barrier height and there was a free bond, the ions will hop to a nearby vacant site. In this study, the mass of $\mathrm{Li}^{+}$ions was set to be $1.1525 \times 10^{-26} \mathrm{~kg}$ and the electric field will be the moving force of the $\mathrm{Li}^{+}$ions. The freeflight time and hopping events will be generated using a random number generator with a value of between 0 and 1 . The wave vector, $\vec{k}_{x}$ in the direction of the applied electric field will be selected at the beginning of the simulation as the initial condition of $\mathrm{Li}^{+}$ions. The distance of $\mathrm{Li}^{+}$ions travelled can be determined by:

$$
l=d \frac{\sqrt{p}}{(1-p)}
$$

where $d$ represents the lattice spacing and $p$ is the probability of observing an open bond at a nearby vacant site. The probability $p$ is generated using a random number generator, $0 \leq p \leq 1$, corresponding to the randomly appeared open bond in a polymer chain segment. The way of the ions transport in the polymer chain is known as "hopping." Basically, ions that received enough energy to overcome the energy barrier height will hop to a nearby open bond, and it is a thermally activated process given by [4]:

$$
s=v_{o} \exp \left[-\frac{\left(E_{i}-E_{f}\right)}{k T}\right]
$$

, where $\left(E_{i}-E_{f}\right)$ is the energy barrier height, $v_{o}$ is the escaping frequency of $\mathrm{Li}^{+}$ions, $T$ is the temperature in Kelvin, $k$ represents the Boltzmann constant, $E_{i}$ and $E_{f}$ are the energy of the ions before and after hopping, respectively. The activation energy is set to be $(<0.2 \mathrm{eV})$ as it was appropriate for SPEs [20]. The motion of $\mathrm{Li}^{+}$ions is simulated to occur randomly within a time frame from $t$ to $t+0.01$ ps with their position updated every $0.01 \mathrm{ps}$. The wave vector obtained from the drifting process will be transferred to the hopping process for the verification of the hopping mechanism of $\mathrm{Li}^{+}$ions and the state of $\mathrm{Li}^{+}$ions after the hopping event. With all the parameters at hand, the drift velocity of $\mathrm{Li}^{+} v$, mobility $\mu$ under the influence of electric field $E$ using the following equation:

$$
\mu=\frac{v}{E}
$$

With mobility of ions obtained, the electric field dependent conductivity is calculated using:

$$
\sigma=n q \mu
$$

, where $n$ represents the concentration of ions, $q$ is the total number of charged transferred by ions, and $\mu$ is the mobility of ions. The current density, $J$ is then calculated using Ohm's law:

$$
J=\sigma E
$$

\section{Recurrence Relation}

The lithium transference number is defined as the number of moles of lithium-ion transferred for one Faraday of charge transferred. In polymer electrolytes, the cation transference number is obtained by dividing the cation number over the number of ions transport across the cell. Current is the product due to transportation of $\mathrm{Li}^{+}$ions. As such, the lithium transference number is determined using the ratio of steady-state current over the initial current in SPE. 
In this work, the lithium transference number of PMMA SPEs is obtained using recurrence relation and the simulated current density. The transference number, $t_{+\mathrm{si}}$ is derived based on recurrence relation developed by Matsuo et al. [21] and the steady-state current method introduced by Evans et al. [19]. Also, the initial and steady-state current densities in MC simulation are obtained through Ramo's theorem [22].

The current density is given by $i(t)=q v / d$, where $v$ represents the charge velocity, $q$ is the amount of charge transferred, and $d$ is the separation distance. The reference lithium transference number, $t_{+s i}$ of PMMA-LiCF${ }_{3} \mathrm{SO}_{3}-\mathrm{EC}$ is calculated as [19]:

$$
t_{+s i}=\frac{I_{s s(r e f)}}{I_{o}}
$$

, where $I_{\mathrm{o}}$ and $I_{\mathrm{ss}(\mathrm{ref})}$ is the measured initial and reference current densities for plasticized PMMA polymer electrolytes. $I_{\mathrm{ss}(\mathrm{ref})}$ is used as reference current density for obtaining lithium transference number in PMMA-EC- $\mathrm{LiCF}_{3} \mathrm{SO}_{3}-\mathrm{SiO}_{2}$ using recurrence relation. The lithium transference number of PMMA$\mathrm{EC}-\mathrm{LiCF}_{3} \mathrm{SO}_{3}-\mathrm{SiO}_{2}$ is calculated as:

$$
t_{+s i}=\left(1+\frac{I_{s s I}}{I_{s s(r e f)}}\right) t_{+r e f}
$$

When more than one composition is incorporated into the mixture, this equation can be generalized using the recurrence relation, in which lithium transference number for various composition in polymer electrolytes is given as:

$$
t_{+s i}=\left(1+\sum_{i=1}^{\infty} \frac{I_{s s i}}{I_{s s(r e f)}}\right) t_{+r e f}
$$

, where $I_{\mathrm{ssi}}$ is the steady-state current density in PMMA-LiCF $\mathrm{SO}_{3}$-EC with different sizes of $\mathrm{SiO}_{2}$ fillers, $I_{\mathrm{ss}(\mathrm{ref})}$ is the steady-state current density in PMMA- $\mathrm{LiCF}_{3} \mathrm{SO}_{3}-\mathrm{EC}$, and $t_{+\mathrm{ref}}$ is the lithium transference number of PMMA-LiCF $\mathrm{SO}_{3}$-EC sample.

It is similar to the general expression of recurrence equation, $y_{1}=\left(1+a_{0} \Sigma_{i=1}^{\infty} x_{i-1}\right) b_{0}$, where $a_{0}=\frac{1}{I_{s s(r e f)}}$ and $b_{0}=t_{+r e f}$. The unity describes the mobile $\mathrm{Li}^{+}$ ions successfully travelling through the electrolyte by overcoming the barriers in the solid polymer electrolytes.

In this work, the ionic conductivity and steadystate current density of PMMA- $\mathrm{LiCF}_{3} \mathrm{SO}_{3}-\mathrm{EC}-\mathrm{SiO}_{2}$ are simulated using $\mathrm{MC}$ simulation, and the lithium transference number is calculated using recurrence relation, based on the ratio of MC simulated steadystate current density by using lithium transference number of PMMA- $\mathrm{LiCF}_{3} \mathrm{SO}_{3}-\mathrm{EC}$ as reference. The results obtained are compared with experimental results and data from various works of literature.

\section{Results and Discussion}

\subsection{Ionic Conductivity of SPEs}

Fig. 1 shows the Nyquist of PMMA- $\mathrm{LiCF}_{3} \mathrm{SO}_{3}$-EC SPE film at $27^{\circ} \mathrm{C}$. The bulk resistance, $\mathrm{R}_{\mathrm{b}}$ is determined from the Nyquist plot with a value of $97.93 \Omega$. Experimental measurements for PMMA- $\mathrm{LiCF}_{3} \mathrm{SO}_{3}$ EC, PMMA-LiCF $\mathrm{SO}_{3}-\mathrm{EC}-\mathrm{SiO}_{2}(\leq 10 \mu \mathrm{m})$, and PMMA-LiCF $\mathrm{SO}_{3}-\mathrm{EC}-\mathrm{SiO}_{2}(\leq 12 \mathrm{~nm})$ is tabulated in Table 1 . The ionic conductivity obtained via MC simulation is shown in Fig. 2, and results from MC simulation agree well with experimentally obtained data.

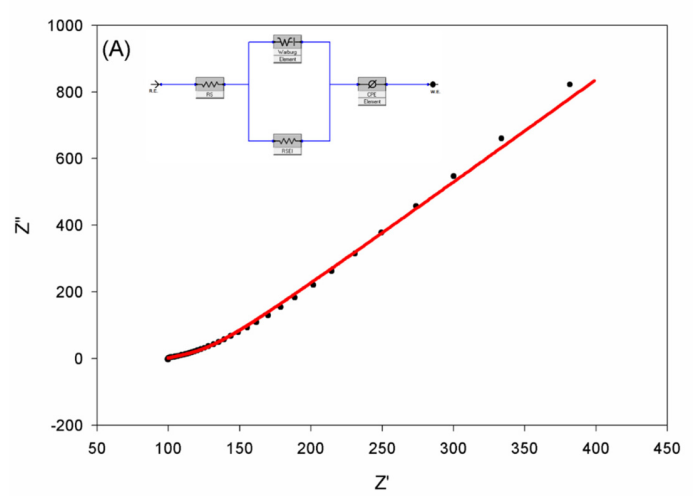

Fig. 1. Nyquist plot of PMMA- $\mathrm{LiCF}_{3} \mathrm{SO}_{3}-\mathrm{EC}$ at room temperature and its equivalent circuit (inset).

Table 1. Ionic conductivity values from measurements

\begin{tabular}{cccc}
\hline \hline SPE Sample & Sample Composition & Ionic Conductivity $(\mathrm{S} / \mathrm{cm})$ & Number of ions \\
\hline PMMA 1 & $\mathrm{PMMA}-\mathrm{LiCF}_{3} \mathrm{SO}_{3}-\mathrm{EC}$ & $8.60 \times 10^{-5}$ & $8.50 \times 10^{10}$ \\
PMMA 2 & $\mathrm{PMMA}-\mathrm{LiCF}_{3} \mathrm{SO}_{3}-\mathrm{EC}-\mathrm{SiO}_{2}(\leq 10 \mu \mathrm{m})$ & $2.35 \times 10^{-4}$ & $2.30 \times 10^{11}$ \\
PMMA 3 & $\mathrm{PMMA}-\mathrm{LiCF}_{3} \mathrm{SO}_{3}-\mathrm{EC}-\mathrm{SiO}_{2}(\leq 12 \mathrm{~nm})$ & $3.79 \times 10^{-4}$ & $3.80 \times 10^{11}$ \\
\hline
\end{tabular}




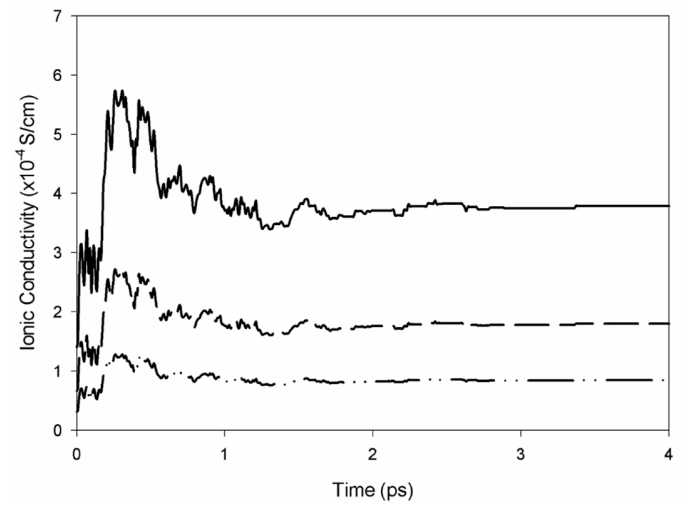

Fig. 2. Monte Carlo ionic conductivity simulation of PMMA 1 (dash-dot line), PMMA 2 (dash line), and PMMA 3 (solid line) SPE samples.

It is shown that PMMA1 sample which does not contain ceramic filler has the lowest conductivity of $8.60 \times 10^{-5} \mathrm{~S} / \mathrm{cm}$, a value comparable to work from Pal et al. [23], where they reported a conductivity of $3.52 \times 10^{-5} \mathrm{~S} / \mathrm{cm}$ for plasticized $\mathrm{PMMA}-\mathrm{LiClO}_{4}$. The low ionic conductivity is mainly contributed by the crystallinity nature of PMMA at room temperature, where $\mathrm{Li}^{+}$ions are believed to suffering from low mobility and are trapped within the polymer chain.

With the addition of $\mathrm{SiO}_{2}(\leq 10 \mu \mathrm{m})$, ionic conductivity of $2.35 \times 10^{-4} \mathrm{~S} / \mathrm{cm}$ is achieved for PMMA2 sample. Chew et al. [24] also reported an improvement in ionic conductivity when they added micron size $\mathrm{SiO}_{2}$ particles into PMMA based polymer electrolytes. They reported an ionic conductivity of $2.15 \times 10^{-4} \mathrm{~S} / \mathrm{cm}$ for PMMA-LiCF $\mathrm{SO}_{3}-\mathrm{EC}-\mathrm{SiO}_{2}$, an improvement from $1.36 \times 10^{-5} \mathrm{~S} / \mathrm{cm}$ without $\mathrm{SiO}_{2}$ fillers in their study.

In this study, nano-sized $\mathrm{SiO}_{2}$ filler is also added into the polymer matrix. The addition of nano-sized filler further increases the ionic conductivity up to $3.79 \times 10^{-4} \mathrm{~S} / \mathrm{cm}$ for PMMA3 samples. The improvement in ionic conductivity agrees well with $[25,26]$ findings where conductivity enhancement increases with increasing effective surface area of filler grains, as nano-sized $\mathrm{SiO}_{2}$ has a greater surface area than micron-sized $\mathrm{SiO}_{2}$ fillers. The improvement in ionic conductivity is associated with the increase in conduction pathway benefitted from the larger effective surface area of $\mathrm{SiO}_{2}$ particles.

Moreover, the addition of $\mathrm{SiO}_{2}$ fillers disrupts the crystal structure of PMMA matrix. As a result, it low- ers the ionic attraction force and improves $\mathrm{Li}^{+}$ions chain mobility. Dissanayake et al. [25] studied the effect of particle size on the ionic conductivity of PEO based polymer electrolytes. They reported the conductivity was significantly improved with the smallest filler size having the larger effective surface area. By decreasing the particle size from $10 \mu \mathrm{m}$ to $10 \mathrm{~nm}$, ionic conductivity was increased by one order of magnitude at $70^{\circ} \mathrm{C}$.

Furthermore, the improvement in ions mobility is also verified through MC simulation. Results from simulation show an increase in the number of ions travelling through the polymer, from $8.50 \times 10^{10}$ for PMMA1 samples up to $3.80 \times 10^{11}$ for PMMA3 samples. The increasing number of ions travelling through the polymer is directly related to the mobility improvement of $\mathrm{Li}^{+}$ions, since there are more space and larger free volume in the polymer matrix for $\mathrm{Li}^{+}$ ions to travel around more easily [25,27].

\subsection{Transference number calculation using recur- rence relation}

Fig. 3 shows the dc polarization curve for PMMA1 samples, the lithium transference number is calculated using Bruce-Vincent method developed by Bruce et al. [19], and it is found to be 0.088. The obtained lithium transference number for PMMA1 samples is used as a reference for the calculation of lithium transference number for PMMA2 and PMMA3 samples by using recurrence relation and MC simulation obtained current density. Fig. 4 compares the experimentally obtained steady-state current density with MC simulated current density under

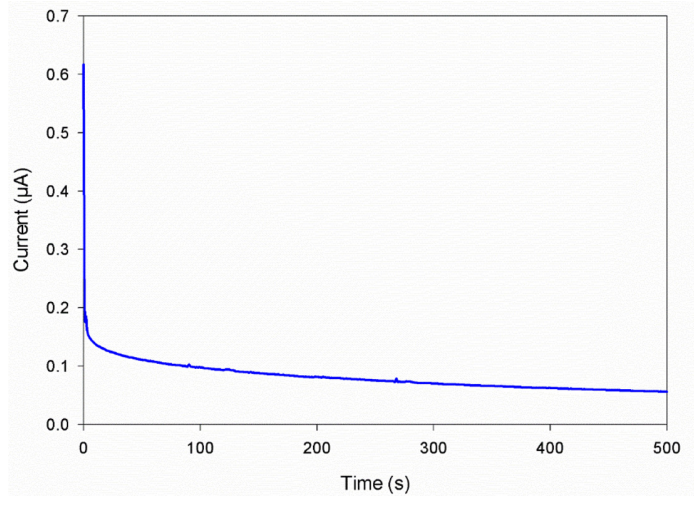

Fig. 3. DC polarization curve for PMMA- $\mathrm{LiCF}_{3} \mathrm{SO}_{3}-\mathrm{EC}$ with an applied de voltage of $20 \mathrm{mV}$. 


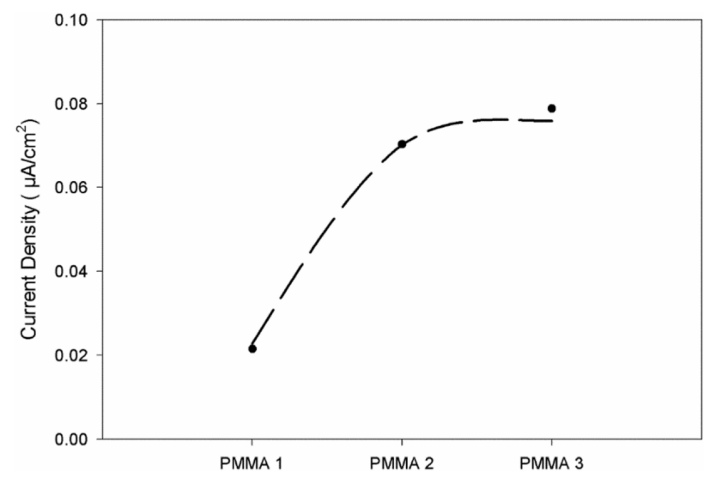

Fig. 4. Steady-state current density of PMMA SPEs with and without $\mathrm{SiO}_{2}$ fillers (dashed line: $\mathrm{MC}$ simulation, dotted: Measurements).

an electric field of $10 \mathrm{~V} / \mathrm{m}$ for PMMA1, PMMA2, and PMMA3 samples, respectively.

It is known that cations are responsible for the generation of electricity inside the battery, and the current density produced is dependent on the ionic conductivity of SPE inside the battery. As a result, PMMA1 samples that have the lowest ionic conductivity produces the lowest current density of $0.0214 \mu \mathrm{A} / \mathrm{cm}^{2}$, and the ionic conductivity increases up to $0.0703 \mu \mathrm{A} / \mathrm{cm}^{2}$ for PMMA 2 samples with the addition of $\mathrm{SiO}_{2}(\leq 10 \mu \mathrm{m})$. The highest current density of $0.0758 \mu \mathrm{A} / \mathrm{cm}^{2}$ is obtained for PMMA3 samples that exhibit the maximum ionic conductivity. With the current density obtained from all samples and lithium transference number for PMMA1 samples, the lithium transference number for PMMA2 and PMMA3 samples are calculated using recurrence relation. Table 2 shows the transference number of PMMA- $\mathrm{LiCF}_{3} \mathrm{SO}_{3}$-EC solid polymer electrolytes with and without $\mathrm{SiO}_{2}$ fillers.

Table 3 shows the lithium transference obtained in this work compared to the lithium transference number obtain from other literature, and it is shown that the lithium transference number obtained using recurrence relation is reasonable. The highest lithium transference number obtained in this study is 0.4105 for PMMA-LiCF $\mathrm{SO}_{3}-\mathrm{EC}-\mathrm{SiO}_{2}(\leq 12 \mathrm{~nm})$, which is comparable to lithium transference number reported by Xiao et al. [9] in their study of P(VDF-HFP)PMMA hybrid polymer electrolytes doped with $\mathrm{ZrO}_{2}$ particles. Furthermore, Liu et al. [28] reported a maximum lithium transference number of 0.39 for PEO CPEs doped with Ga-LLZO nanofillers. Wang et al. [29] and Liu et al. [30] obtained lithium transference number of up to 0.54 and 0.56 respectively in their study of PEO gel polymer electrolytes (GPEs) doped

Table 2. Lithium transference number calculated using recurrence relation

\begin{tabular}{cccc}
\hline \hline Sample ID & Sample Composition & Current Density $\left(\mu \mathrm{A} / \mathrm{cm}^{2}\right)$ & Lithium transference number $\left(\mathrm{t}^{+}\right)$ \\
\hline PMMA 1 & PMMA-LiCF $_{3} \mathrm{SO}_{3}-\mathrm{EC}$ & 0.0215 & 0.088 \\
PMMA 2 & PMMA-LiCF $_{3} \mathrm{SO}_{3}-\mathrm{EC}-\mathrm{SiO}_{2}(\leq 10 \mu \mathrm{m})$ & 0.0703 & 0.3757 \\
PMMA 3 & PMMA-LiCF $_{3} \mathrm{SO}_{3}-\mathrm{EC}-\mathrm{SiO}_{2}(\leq 12 \mathrm{~nm})$ & 0.0788 & 0.4105 \\
\hline
\end{tabular}

Table 3. Lithium transference number obtained in this work compared to other researchers.

\begin{tabular}{|c|c|c|c|}
\hline Composition & Type & Reference & $\mathrm{t}^{+}$ \\
\hline PMMA-LiCF $\mathrm{SO}_{3}-\mathrm{EC}$ & Solid & This work & 0.088 \\
\hline PMMA-LiCF $\mathrm{SO}_{3}-\mathrm{EC}-\mathrm{SiO}_{2}(\leq 10 \mu \mathrm{m})$ & Solid & This work & 0.3757 \\
\hline PMMA-LiCF ${ }_{3} \mathrm{SO}_{3}-\mathrm{EC}-\mathrm{SiO}_{2}(\leq 12 \mathrm{~nm})$ & Solid & This work & 0.4105 \\
\hline PEO-PVP-LiNO 3 & Solid & Jinisha $[20]$ & 0.332 \\
\hline $\mathrm{P}(\mathrm{VDF}-\mathrm{HFP})-\mathrm{PMMA}-\mathrm{LiPF}_{6}-\mathrm{EC}-\mathrm{ZrO}_{2}$ & Solid & Xiao [9] & $0.28-0.41$ \\
\hline P(VDF-HFP)-PMMA-LiPF 6 -EC & Solid & Xiao [9] & 0.16 \\
\hline PEO-LiCF ${ }_{3} \mathrm{SO}_{3} \mathrm{EC}-\mathrm{SiO}_{2}(\leq 12 \mathrm{~nm})$ & Gel & Wang [29] & 0.54 \\
\hline PEO-LiBF $4-E C-\mathrm{SiO}_{2}(\leq 12 \mathrm{~nm})$ & Gel & Liu [30] & $0.34-0.56$ \\
\hline PMMA-LiBOB-EC & Gel & Hosseinioun [31] & 0.34 \\
\hline PMMA-LiClO 4 -EC & Gel & Faridi [13] & $0.39-0.42$ \\
\hline
\end{tabular}


with $\mathrm{SiO}_{2}$ nano-particles. Naturally, lithium transference number obtained for GPEs would be higher than that of SPEs, because GPEs are more amorphous than SPEs, and the mobility of $\mathrm{Li}^{+}$ions in GPEs is higher, yielding a higher lithium transference number.

\section{Conclusion}

A sophisticated MC model had been developed in this study, the model is capable of simulating the ionic conductivity of PMMA- $\mathrm{LiCF}_{3} \mathrm{SO}_{3}$-EC of various compositions at room temperature, and the simulation data agree well with experimental results. The results also illustrate that PMMA CPEs with $\mathrm{SiO}_{2}$ particles greatly enhance the ionic conductivity and lithium transference number in comparison with the traditional SPEs at room temperature. Since cations are the primary charge carriers in the system, the enhancement in ionic conductivity produces higher current density and larger cationic transference number. The highest ionic conductivity and current density achieved at room temperature in this work are $3.79 \times 10^{-4} \mathrm{~S} / \mathrm{cm}$ and $0.0788 \mu \mathrm{A} / \mathrm{cm}^{2}$, respectively, for PMMA-LiCF $\mathrm{SO}_{3}-\mathrm{EC}-\mathrm{SiO}_{2}(\leq 12 \mathrm{~nm})$. The highest lithium transference number recorded is 0.4105 with $3.8 \times 10^{11} \mathrm{~cm}^{-3} \mathrm{Li}^{+}$ions travelling through the PMMA polymer electrolyte for nanosized $\mathrm{SiO}_{2}$ particles in the simulation. Lastly, it is shown that the addition of inorganic particle into the polymer matrix greatly enhances the ionic conductivity and lithium transference number of traditional electrolytes system. CPEs not only has a greater ionic conductivity and lithium transference number than traditional polymer electrolytes system, but several recent studies also show that CPEs exhibit better thermal stability and energy density [16,32].

\section{Declaring of Competing Interest}

I hereby declare that I have no competing financial interest or personal relationship that could have appeared to influence the work reported in this paper.

\section{Acknowledgement}

This work is supported by FRGS/ 2019, Ministry of Higher Education, Malaysia.

\section{Reference}

[1] R. C. Agrawal, G. P. Pandey, J. Phys. D. Appl. Phys., 2008, 22(41), 223001.

[2] K. Pożyczka, M. Marzantowicz, J. R. Dygas, F. Krok, Electrochim. Acta., 2017, 227, 127-135.

[3] S. Li, S. Q. Zhang, L. Shen, Q. Liu, J. B. Ma, W. Lv, Y. B. He, Q. H. Yang, $A d v$. Sci., 2020, 7(5), 1903088.

[4] R. C. Agrawal, R. K. Gupta, J. Mater. Sci., 1999, 34(6), 1131-1162.

[5] L. R. A. K. Bandara, M. A. K. L. Dissanayake, B. Mellander, Electrochim. Acta., 1998, 43(10-11), 14471451.

[6] M. Forsyth, D. R. MacFarlane, A. Best, J. Adebahr, P. Jacobsson, A. J. Hill. Solid State Ionics., 2002, 147(3-4), 203-211.

[7] L. Sampath Kumar, P. Christopher Selvin, S. Selvasekarapandian, Polym. Bull., 2020.

[8] X. Qian, N. Gu, Z. Cheng, X. Yang, E. Wang. S. Dong, Mater. Chem. Phys., 2002, 74(1), 98-103.

[9] W. Xiao, Z.Y Wang, Y. Zhang, R. Fang, Z.Yuan, C. Miao, X. Yan, Y. Jiang, J. Power Sources., 2018, 382, 128-134.

[10] S. D. Druger, M. A. Rather, A, Nitzan. Solid State Ionics., 1983, 9, 1115-1120.

[11] A. Wagner, H. Kliem, J. Appl. Phys., 2002, 91(10), 6638-6649.

[12] Sudaryanto, E. Yulianti, H. Jodi, Polym Plast Technol Eng., 2015, 54(3), 290-295.

[13] M. Faridi, L. Naji, S. Kazemifard, N. Pourali, Chem. Pap., 2018, 72(9), 2289-2300.

[14] C. C. Sun, A. H. You, L. L. Teo, J. Polym. Eng., 2019, 39(7), 612-619.

[15] S. Kurapati, S. S. Gunturi, K. J. Nadella, H. Erothu, Polym. Bull., 2019, 76(10), 5463-5481.

[16] Y. S. Lim, H. A. Jung, H. Hwang, Energies., 2018, 11(10), 2559-2569.

[17] I. Zakariya'u, B. Gultekin, V. Singh, P. K. Singh, High Perform Polym., 2020, 32(2), 201-207.

[18] Y. L. Yap, A. H. You, L. L. Teo, Ionics., 2019, 25(7), 3087-3098.

[19] J. Evans, C. A. Vincent, P. G. Bruce, Polymer., 1987, 28(13), 2324-2328.

[20] B. Jinisha, K. M. Anilkumar, M. Manoj, V. S. Pradeep, S. Jayalekshmi, Electrochim. Acta., 2017, 235, 210-222.

[21] K. Matsuo, M. C. Teich, B. E. A. Saleh, J. Light. Technol., 1985, 3(6), 1223-1231.

[22] S. Ramo. Proceedings of the IRE., 1939, 27(9), 584-585.

[23] P. Pal, A. Ghosh, Solid State Ionics., 2018, 319, 117-124.

[24] K. W. Chew, K. W. Tan, Int. J. Electrochem. Sci., 2011, 6(11), 5792-5801.

[25] M. A. K. L. Dissanayake, P. A. R. D. Jayathilaka, R. S. P. Bokalawala, I. Albinsson, B. E. Mellander, J. Power Sources., 2003, 119, 409-414.

[26] H. M. J. C. Pitawala, M. A. K. L. Dissanayake, V. A. Seneviratne, Solid State Ionics., 2007, 178(13-14), 885- 
888.

[27] G. B. Appetecchi, F. Croce, B. Scrosati, J. Power Sources., 1997, 66(1-2), 77-82.

[28] Z. Li, H. M. Huang, J. K. Zhu, J. F. Wu, H. Yang, L. Wei, X. Guo, ACS Appl. Mater. Interfaces., 2019, 11(1), 784-791.

[29] W. Wang, P. Alexandridis, Polymers., 2016, 8(11), 387.
[30] Y. Liu, J. Y. Lee, L. Hong, J. Power Sources., 2004, 129(2), 303-311.

[31] A. Hosseinioun, P. Nürnberg, M. Schönhoff, D. Diddens, E. Paillard, RSC Adv., 2019, 9(47), 2757427582.

[32] P. Yao, H. Yu, Z. Ding, Y. Liu, J. Lu, M. Lavorgna, J. Wu. X. Liu. Front. Chem., 2019, 7, 552. 